\title{
Influences of Holes Arrangement on Creep Characteristic of Nickel-Base Single Crystal Alloy Blade Cooling Holes
}

\author{
Lei Li, ${ }^{1}$ Liangbo Ao, ${ }^{1}$ Gongnan Xie, ${ }^{2}$ Xinmei Wang, ${ }^{1}$ and Gang Cao ${ }^{1}$ \\ ${ }^{1}$ Department of Engineering Mechanics, Northwestern Polytechnical University, Xian, Shaanxi 710072, China \\ ${ }^{2}$ School of Mechanical Engineering, Northwestern Polytechnical University, Xian, Shaanxi 710072, China \\ Correspondence should be addressed to Lei Li; lileinpu@nwpu.edu.cn
}

Received 27 May 2013; Revised 16 August 2013; Accepted 19 August 2013

Academic Editor: Steven Suib

Copyright (c) $2013 \mathrm{Lei} \mathrm{Li} \mathrm{et} \mathrm{al.} \mathrm{This} \mathrm{is} \mathrm{an} \mathrm{open} \mathrm{access} \mathrm{article} \mathrm{distributed} \mathrm{under} \mathrm{the} \mathrm{Creative} \mathrm{Commons} \mathrm{Attribution} \mathrm{License,} \mathrm{which}$ permits unrestricted use, distribution, and reproduction in any medium, provided the original work is properly cited.

\begin{abstract}
Film cooling technology is developed to enhance the temperature resistant of nickel-base single crystal alloy blade. The shape, dimension, and arrangement of cooling holes impact the blade strength and life grievously. In this paper, the influences of holes arrangement on creep characteristic of cooling holes in the plate sample are investigated. The constitutive model for creep considering both cavitation and degradation damage is developed to predict the creep behavior of cooling holes. Results show that there are stress interferences among cooling holes. The distance and radius of the cooling holes impact the creep behavior of cooling holes seriously. Decreasing horizontal distance of the holes results in creep time reducing. On the contrary, increasing the vertical distance of the holes makes the creep time reduced.
\end{abstract}

\section{Introduction}

Nickel-base single crystal alloy has been developed for gas turbine blade applications because of the property of creep and fatigue resistance in high temperature. Due to the turbine entry temperature increasing, the blades have to be cooled in order to work in a suitable environment. Film cooling technology using relative cooler air from the cooling holes to impede the blade from the higher temperature gas is widely applied in high-pressure turbine blade as an important heat protection method. But the cooling holes destroy the structure integrity of blades and cause the regions near the cooling holes to suffer in high multiaxial stress satiation and become the key regions of crack initialing. It has been reported that many cooling blades have been broken near the cooling holes $[1,2]$.

Most of recent researches have focused on the influences of different shape and arrangement of cooling holes on the cooling effectiveness. Thole et al. [3] compared cooling characteristic of three different cooling holes geometries. Gao et al. [4] listed four kinds of film cooling holes configurations and investigated film cooling effectiveness along the axis and with a compound angle. Lu et al. [5] presented five arrangements of cooling holes and introduced the influences of the shape in different arrangements.

However, little attentions have focused on the mechanical behavior of film cooling holes up to now. In this paper, the creep characteristic of nickel-base single crystal alloy cooling holes is investigated. Firstly, the creep characteristic of the cooling holes is predicted on basis of the crystal plasticity theory with the double parameter creep model. Secondly, the influences of holes arrangement on the creep behaviors of cooling holes are investigated.

\section{The Geometry Model of Cooling Holes}

The model for film cooling holes creep prediction is designed in order to reflect the actual working condition, shown in Figure 1. The whole model has three column cylinder holes with the same radius in a staggered arrangement, which is $10 \mathrm{~mm}$ in height, $5 \mathrm{~mm}$ in width, and $2 \mathrm{~mm}$ in depth. The model is subjected to a uniform tensile load $\sigma$ on the up and down end along $\langle 001\rangle$ crystallographic orientation. In this work, four cases shown in Table 1 with different, $h$, and $R$ values are considered. In order to get the same average stress 


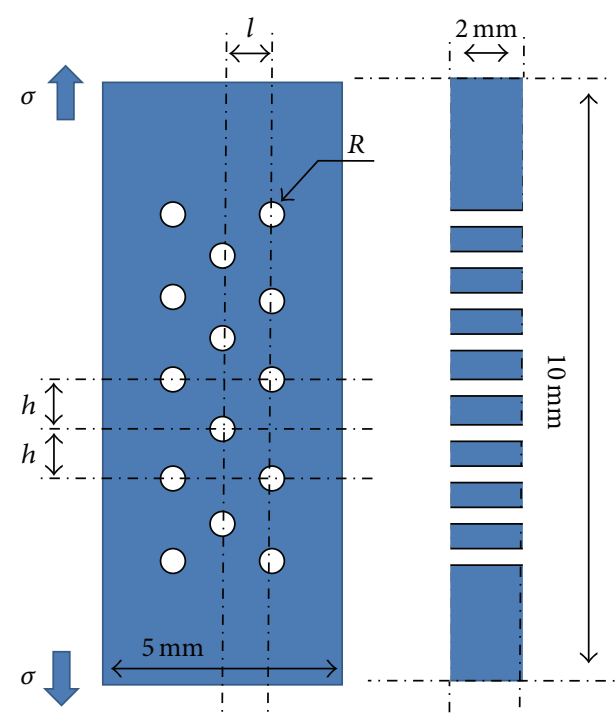

FIGURE 1: Schematic map of the film cooling holes geometry model.

TABLE 1: Four cases for cooling holes creep characteristic.

\begin{tabular}{lcccc}
\hline Case & $l / \mathrm{mm}$ & $h / \mathrm{mm}$ & $R / \mathrm{mm}$ & $\sigma / \mathrm{Mpa}$ \\
\hline 1 & 1.0 & 0.48 & 0.2 & 350.0 \\
2 & 0.8 & 0.48 & 0.2 & 350.0 \\
3 & 1.0 & 0.53 & 0.2 & 350.0 \\
4 & 1.0 & 0.48 & 0.25 & 333.33 \\
\hline
\end{tabular}

at the minimum area section in different cases, the load $\sigma$ is adjusted when the hole radius changes.

\section{Creep Prediction Model}

Nickel-base single crystal alloy is a classical anisotropy material with two-phase microstructure, $\gamma$ and $\gamma^{\prime}$ phases, which are based and refined phase, relatively. Taylor [6] and Taylor and Elam [7] develop the crystallographic constitutive relationship to describe the crystal deformation behavior with slip mechanism. The resolved shear stress $\tau^{(\alpha)}$ on $\alpha$ slip system is defined as [8]

$$
\tau^{(\alpha)}=\mathbf{P}^{(\alpha)}: \sigma
$$

where $\mathbf{P}^{(\alpha)}$ is the Schmidt tensor factor $\boldsymbol{\sigma}$ is stress tensor. $\mathbf{P}^{(\alpha)}$ is given by

$$
\mathbf{P}^{(\alpha)}=\frac{1}{2}\left(\mathbf{m}^{(\alpha)} \mathbf{n}^{(\alpha)^{T}}+\mathbf{n}^{(\alpha)} \mathbf{m}^{(\alpha)^{T}}\right)
$$

where $\mathbf{n}^{(\alpha)}$ and $\mathbf{m}^{(\alpha)}$ are the unit vectors normal to the slip plane and along the slip direction of the slip system $\alpha$, respectively.

The total strain rate $\dot{\varepsilon}$ is the summation of the elastic strain $\dot{\varepsilon}_{e}$ and nonelastic strain $\dot{\varepsilon}_{c}$ (creep strain), expressed as

$$
\dot{\varepsilon}=\dot{\varepsilon}_{e}+\dot{\varepsilon}_{c}
$$

TABLE 2: The parameter value of creep damage model at $900^{\circ} \mathrm{C}$.

\begin{tabular}{lccc}
\hline$n$ & $m$ & $C$ & $P$ \\
\hline 40.0 & 1.01 & 50 & 0.98 \\
\hline
\end{tabular}

The elastic strain rate $\dot{\varepsilon}_{e}$ can be got by (1). The creep strain rate $\dot{\varepsilon}_{c}$ relates the resolved shear strain rate as follows:

$$
\dot{\varepsilon}_{c}=\sum_{\alpha=1}^{N} \dot{\gamma}^{(\alpha)} \mathbf{P}^{(\alpha)}
$$

Research results have shown that the damage mechanism of creep of nickel-base single crystal alloy can be grouped in two categories. One is cavitation controlled damage, initialing at the cast fault. The other is degradation damage causing [9] by the rafting of $\gamma^{\prime}$ phase under the influence of stress and temperature.

The creep damage model considering cavitations and degradation together is described as follows [10]:

$$
\begin{gathered}
\dot{\gamma}=\dot{\gamma}_{i}\left(\frac{1}{1-\omega}\right)^{n} e^{S}, \\
\dot{\omega}=\dot{\omega}_{0} \dot{\gamma}^{m}, \\
\dot{S}=C \dot{\gamma}^{p},
\end{gathered}
$$

where $\dot{\gamma}_{i}=\dot{\gamma}_{0} \tau^{n}, \dot{\gamma}$ denotes the resolved shear creep strain rate, $\omega$ is cavitations damage factor, and $S$ represents the material degradation. $\dot{\gamma}_{0}$ is the initial creep strain rate, $\dot{\omega}_{0}$ the initial damage rate. $n, m, C$, and $p$ are the model parameter, which depend on the temperature.

In order to evaluate the damage level of material degradation, the equation is defined as

$$
D_{S}=\left(\frac{S}{1+S}\right)^{r}
$$

in this work, $r=1$.

The total damage is expressed as

$$
D=D_{S}+\omega
$$

If $D=1$, the material fractures.

\section{Results and Discussion}

4.1. The Creep Characteristic of the Cooling Holes. The above theory has been programmed into a user subroutine of FEA software ABAQUS with UMAT. Nickel-base single crystal superalloy CMSX-4 is used in this paper. According to the sample test, the parameter of the creep damage model at $900^{\circ} \mathrm{C}$ is shown in Table 2.

Figure 2 shows the distribution of the maximum resolved shear stress at different creep time. It can be seen that there are stress interferences among cooling holes. Both higher stress region and lower stress region exist around the cooling holes, marked by A and B in Figure 2(a). The higher stress regions locate the areas between the two cooling holes in 


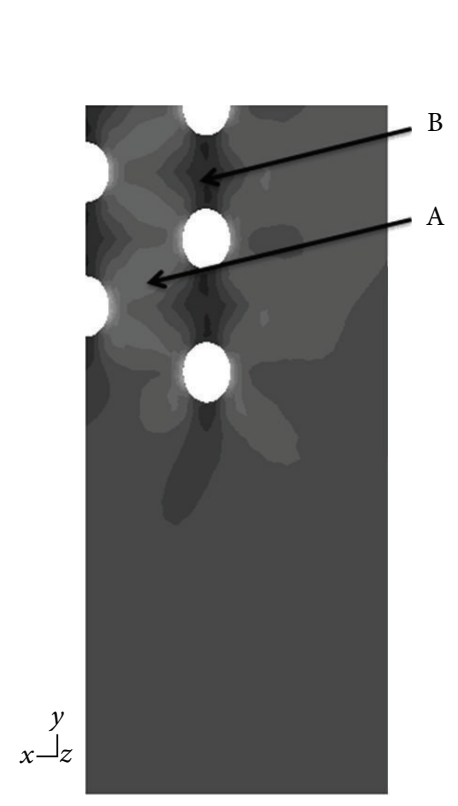

(a) $0.002 \mathrm{~h}$

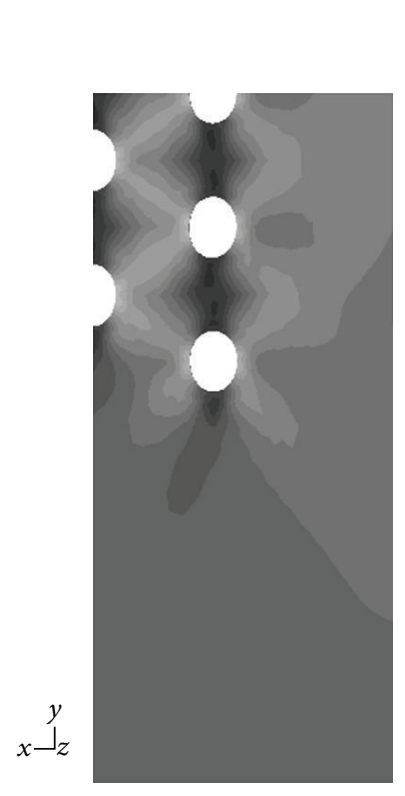

(c) $7.5 \mathrm{~h}$
SDV92

(Avg: 75\%)

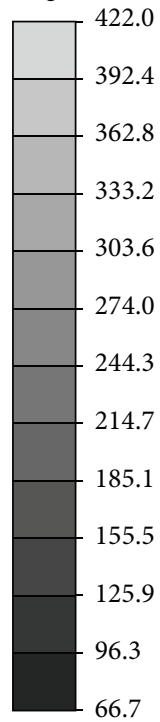

66.7

SDV92

(Avg: 75\%)

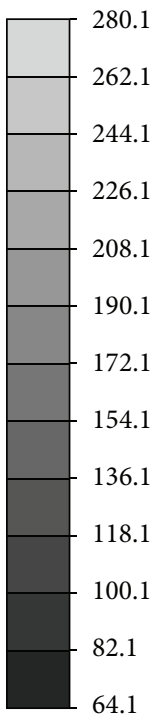

64.1

$y$
$x-z$
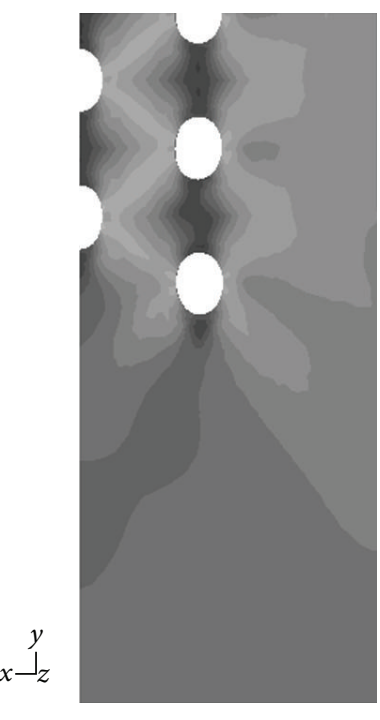

(d) $27.5 \mathrm{~h}$
SDV92

(Avg: $75 \%)$

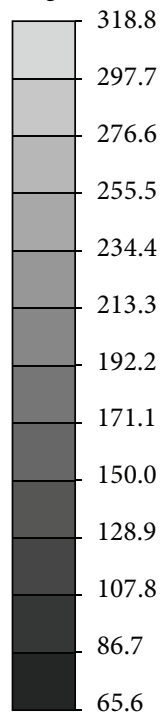

(b) $3.0 \mathrm{~h}$

SDV92

(Avg: $75 \%)$

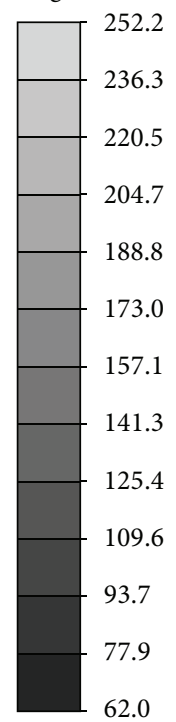

62.0

FIGURE 2: The development of the maximum resolved shear stress at different creep time.

the two adjacent columns. The higher region stress contour shows a band pattern along the line of the two holes center connection. With the creep time increasing, the areas of higher stress region expand. The lower stress regions locate between the two cooling holes in the same column. The stress contour at the lower stress region presents a pattern as diamond. The areas of lower stress reduce continually through the creep time. For developing trend of the whole stress, the value and distribution of the stress redistribute.

Figure 3(a) demonstrates the maximum resolved shear stress of each hole at point A versus creep time. The higher stress regions near the cooling holes have the phenomenon of stress loosen. The resolved shear stress of hole no. 5 is higher than hole no. 4 in the same column. The resolved shear stress of hole no. 2 is higher than the other two holes in the same column. No. 5 has the maximum magnitude. Figure 3(b) gives the strain $\varepsilon_{22}$ of point $A$ along load direction versus creep time. The creep strain increases through the creep time. The distribution of creep strain $\varepsilon_{22}$ is similar with the resolved shear stress.

4.2. Effect of Hole Arrangement. In order to obtain the influences of holes arrangement, three other cases with different $l, h$, and $R$ are investigated. The comparison of creep 


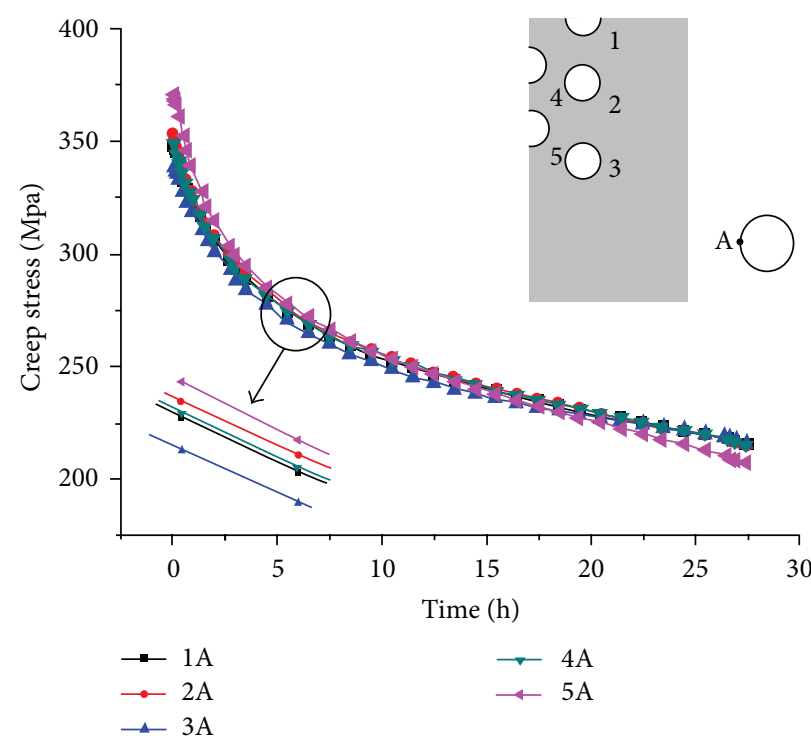

(a) The maximum resolved shear stress versus creep time

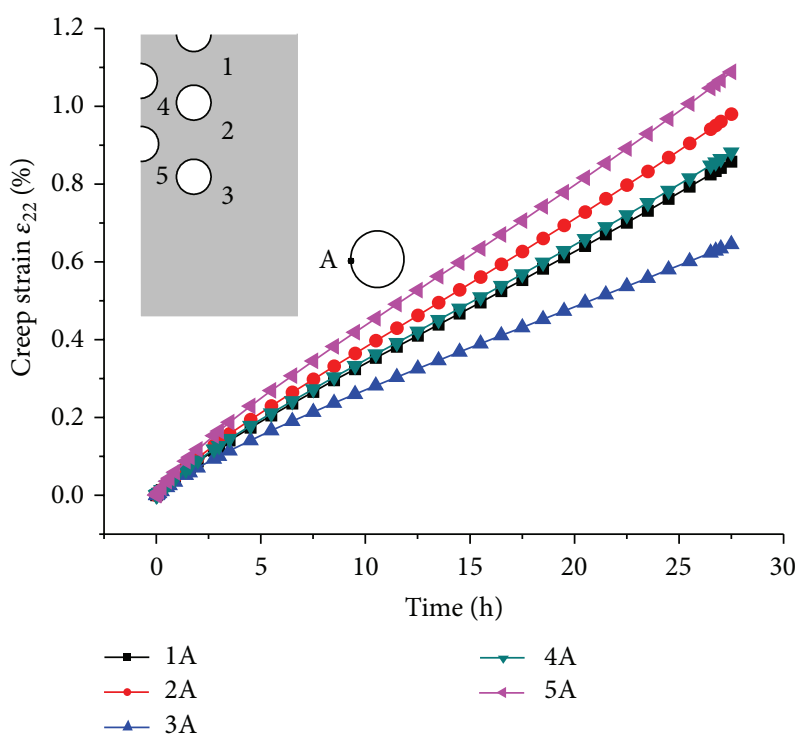

(b) Creep strain $\varepsilon_{22}$ versus creep time

FIGURE 3: The development of stress at the cooling hole.

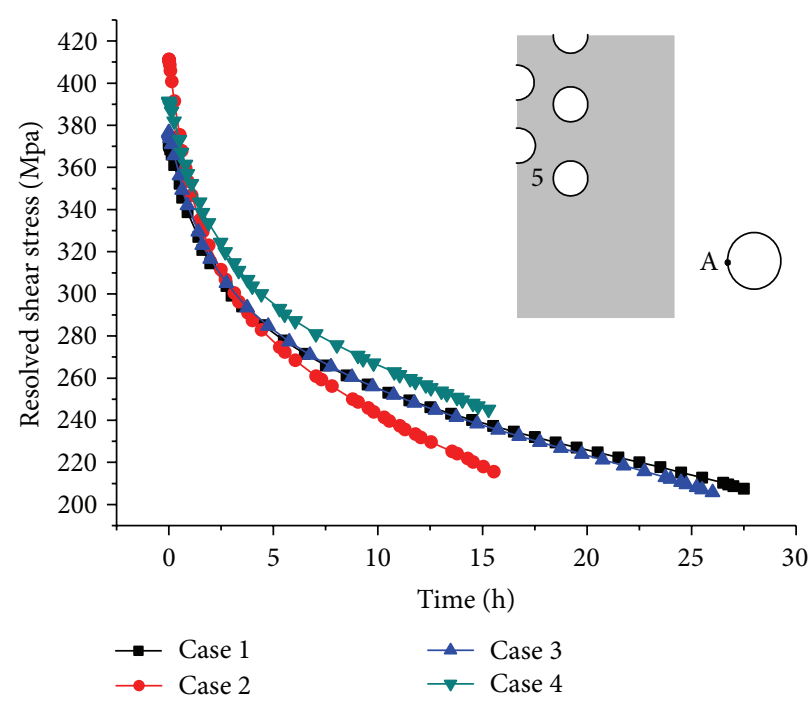

(a) The maximum resolved shear stress versus creep time

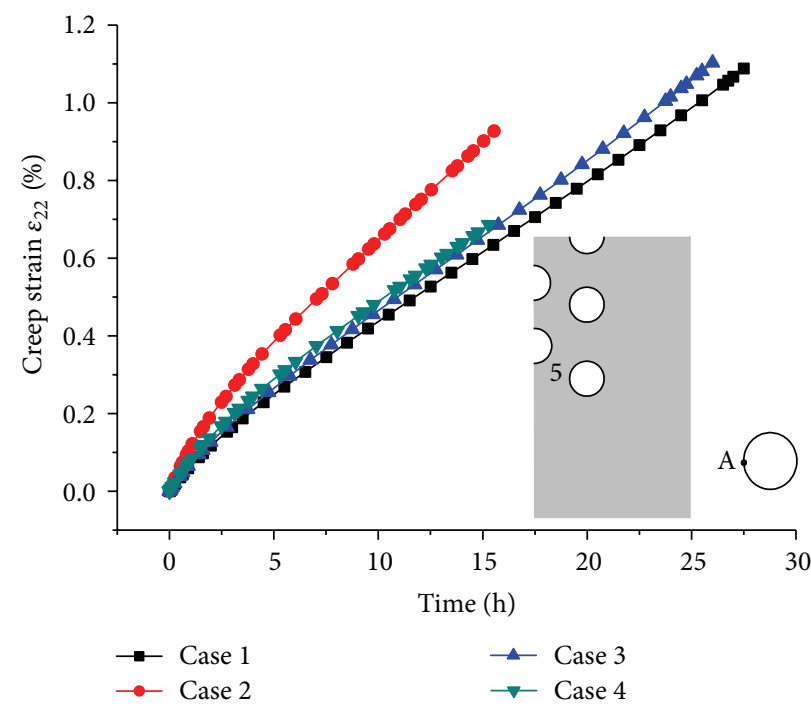

(b) Creep strain $\varepsilon_{22}$ versus creep time

FIgURE 4: The comparison of creep characteristic for the four cases.

characteristic of four cases is shown in Figure 4. The radius of cooling holes impacts the creep behavior seriously, which has the maximum resolved shear stress and shortest creep time. The hole distance also impacts the creep behavior of cooling holes. With decreasing the horizontal hole distance, the creep time reduces evidently. But with the vertical hole distance increasing, the creep time reduces on the contrary. Thus, the film cooling hole should be designed in a suitable distance, not as far as possible.

\section{Conclusions}

This paper investigates the creep characteristic of nickel-base single crystal alloy film cooling holes with creep damage prediction model considering the cavitations and degradation together and presents the influences of the holes arrangement on the creep behavior of cooling holes.

(1) There are both higher stress and lower stress regions around cooling holes. The higher stress regions have the phenomenon of stress loosen. The value and distribution of the cooling holes stress re-distribute along the creep time.

(2) The hole distance and radius impact the creep behavior of the cooling holes seriously. For the model of this paper, decreasing horizontal hole distance results in the creep time reducing. On the contrary, the vertical hole distance increasing makes the creep time reducing. 


\section{Acknowledgments}

National Natural Science Foundation of China (Grant nos. 51205315 and 51210008), Science Foundation of Aeronautics of China (Grant no. 2012ZB53012), and Fundamental Research Foundation of NPU (Grant nos. JCY20130126, JC20120230, and 13GH014610) support this work.

\section{References}

[1] Z. Mazur, A. Luna-Ramírez, J. A. Juárez-Islas, and A. CamposAmezcuaa, "Failure analysis of a gas turbine blade made of Inconel 738LC alloy," Engineering Failure Analysis, vol. 12, no. 3, pp. 474-486, 2005.

[2] R. A. Kupkovits and R. W. Neu, "Thermomechanical fatigue of a directionally-solidified Ni-base superalloy: smooth and cylindrically-notched specimens," International Journal of Fatigue, vol. 32, no. 8, pp. 1330-1342, 2010.

[3] K. A. Thole, M. Gritsch, A. Schulz, and S. Wittig, "Flowfield measurements for film-cooling holes with expanded exits," ASME Paper 96-GT-174, 1996.

[4] Z. Gao, D. P. Narzary, and J. C. Han, "Film cooling on a gas turbine blade pressure side or suction side with axial shaped holes," International Journal of Heat and Mass Transfer, vol. 51, no. 9-10, pp. 2139-2152, 2008.

[5] Y. Lu, D. Allison, and S. V. Ekkad, “Turbine blade showerhead film cooling: influence of hole angle and shaping," International Journal of Heat and Fluid Flow, vol. 28, no. 5, pp. 922-931, 2007.

[6] G. I. Taylor, "Plastic strain in metals," Journal of the Institute of Metals, vol. 62, pp. 307-324, 1938.

[7] G. I. Taylor and C. F. Elam, "The distortion of an aluminum crystal during a tensile test," Proceedings of the Royal Society A, vol. 102, no. 719, pp. 643-667, 1923.

[8] J. Lubliner, Plasticity Theory, Pearson Education, London, UK, 2006.

[9] D. Chatterjee, N. Hazari, N. Das, and R. Mitra, "Microstructure and creep behavior of DMS4-type nickel based superalloy single crystals with orientations near $<001>$ and $<011>$," Materials Science and Engineering A, vol. 528, no. 2, pp. 604-613, 2010.

[10] Z. Wen, N. Hou, and Z. Yue, "Creep behaviors of nickel-based single crystal superalloys compact tension specimen at high temperature," Advanced Materials Research, vol. 146-147, pp. 1322-1326, 2011. 

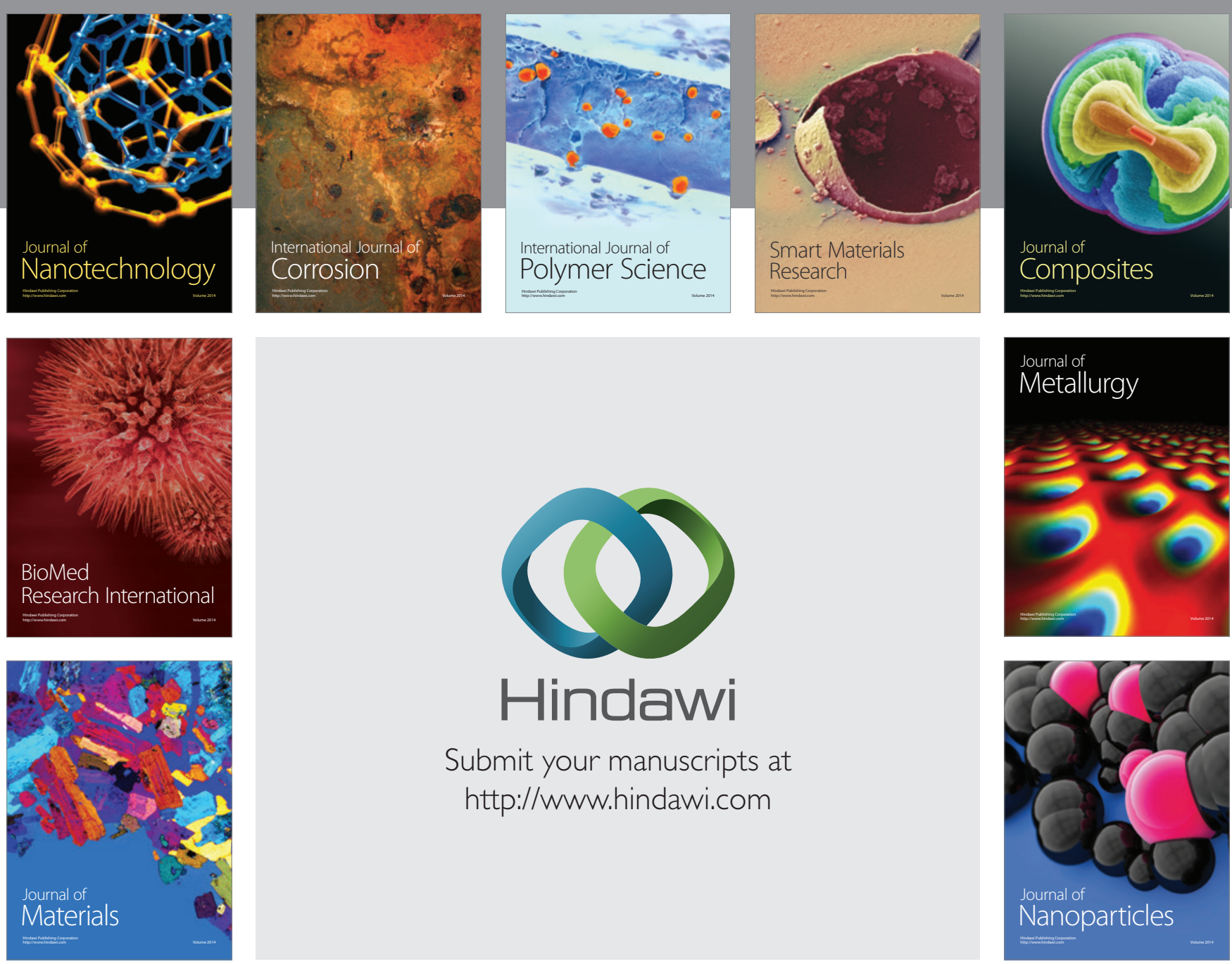

Submit your manuscripts at http://www.hindawi.com
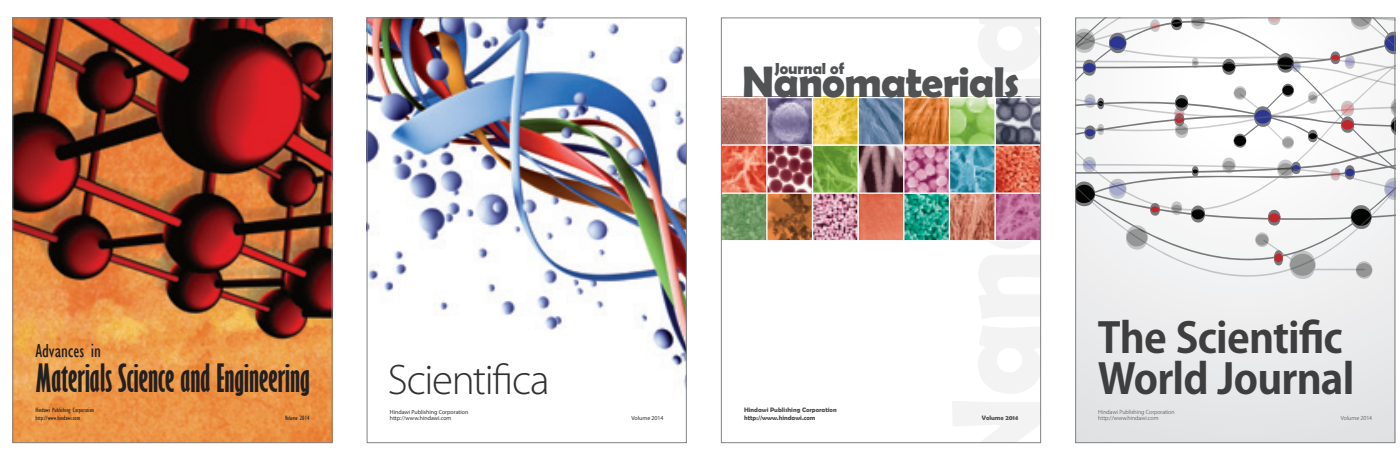

\section{The Scientific World Journal}
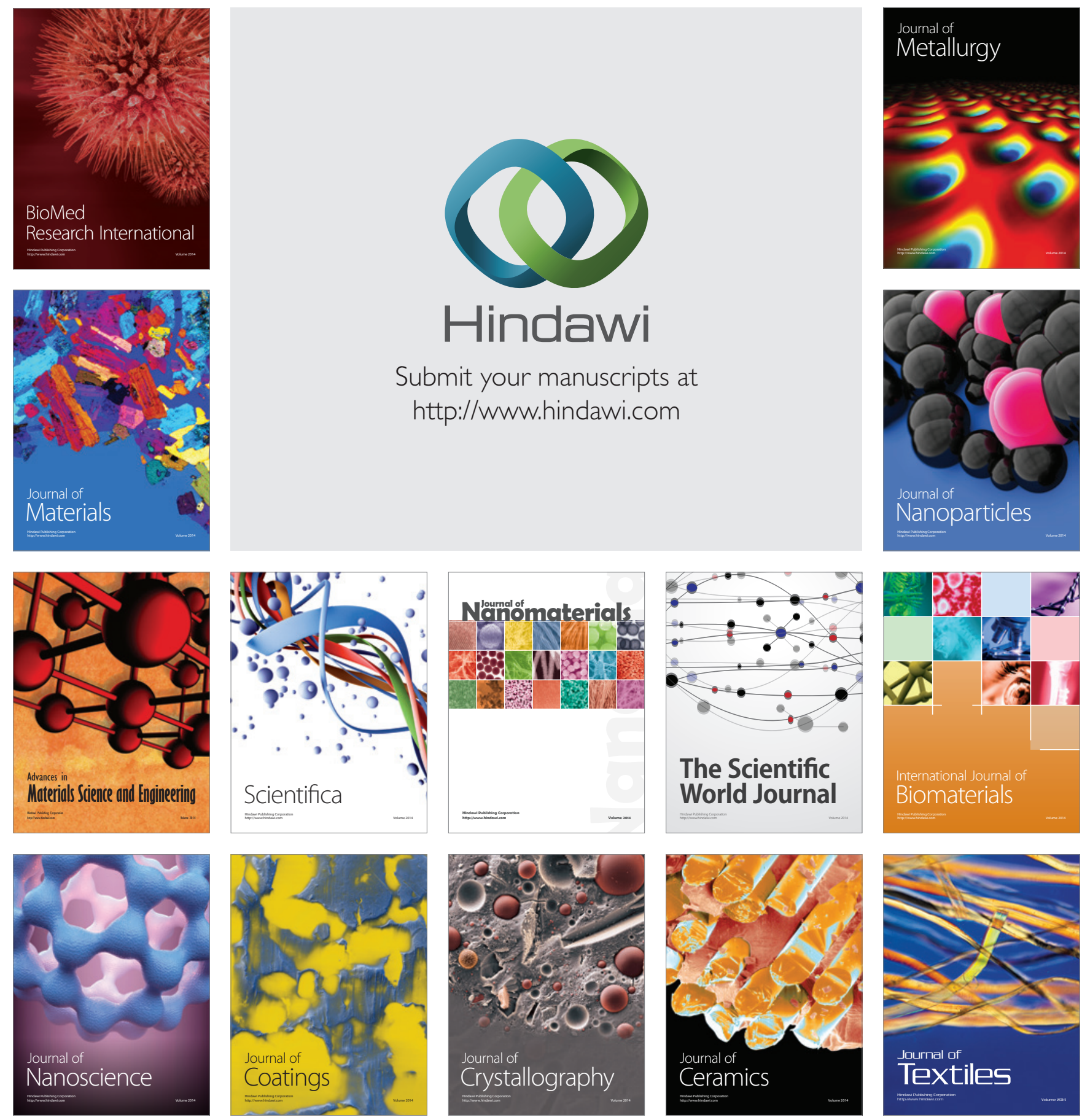